Article

\title{
Screening of Small Molecule Microarrays for Ligands Targeted to the Extracellular Epitopes of Living Cells
}

\section{Jeong Heon Lee ${ }^{1}$, Kai Bao ${ }^{1}$, John V. Frangioni ${ }^{1,2}$ and Hak Soo Choi ${ }^{1,3, *}$}

1 Division of Hematology/Oncology, Department of Medicine, Beth Israel Deaconess Medical Center and Harvard Medical School, Boston, MA 02215, USA;

E-Mails: jlee27@bidmc.harvard.edu (J.H.L.); kbao@bidmc.harvard.edu (K.B.); jfrangio@bidmc.harvard.edu (J.V.F.)

2 Curadel, LLC, 377 Plantation Street, Worcester, MA 01605, USA

3 Department of Cogno-Mechatronics Engineering, Pusan National University, Busan 609-735, Korea

* Author to whom correspondence should be addressed; E-Mail: hchoi@bidmc.harvard.edu; Tel.: +1-617-667-6024; Fax: +1-617-667-0214.

Academic Editor: Ulrich Certa

Received: 3 December 2014 / Accepted: 6 February 2015 / Published: 12 February 2015

\begin{abstract}
The screening of living cells using high-throughput microarrays is technically challenging. Great care must be taken in the chemical presentation of potential ligands and the number of collisions that cells make with them. To overcome these issues, we have developed a glass slide-based microarray system to discover small molecule ligands that preferentially bind to one cell type over another, including when the cells differ by only a single receptor. Chemical spots of $300 \pm 10 \mu \mathrm{m}$ in diameter are conjugated covalently to glass slides using an arraying robot, and novel near-infrared fluorophores with peak emission at $700 \mathrm{~nm}$ and $800 \mathrm{~nm}$ are used to label two different cell types. By carefully optimizing incubation conditions, including cell density, motion, kinetics, detection, etc. we demonstrate that cell-ligand binding occurs, and that the number of cells bound per chemical spot correlates with ligand affinity and specificity. This screening system lays the foundation for high-throughput discovery of novel ligands to the cell surface.
\end{abstract}

Keywords: small molecules; high-throughput screening; live cells; microarrays; cell-based assay; drug discovery 


\section{Introduction}

Extracellular membrane (ECM) receptors are of significant importance to the development of new therapeutic agents, being the molecular targets for more than $60 \%$ of clinical drugs [1,2]. To discover new potential targets and to identify therapeutic agents, various diversity-oriented combinatorial libraries have been developed [3-6]. The small molecule microarray (SMM) is one of the most effective profiling solutions through the use of pre-patterned regions of interest (ROI), which provide chemical identity and functionality [7-11]. Although having significant potential, high-throughput SMM screening is currently limited due to the use of non-physiological contexts (e.g., absence of serum) and non-viable samples (e.g., cell lysates); most current methods also neglect ECM dynamics [12-14]. Microfluidics is a new technology that enables many assays using living cells, but it is not conducive to high-throughput chemical screening [15-18].

A simple alternative approach is direct panning of living cells over ligand-spotted microarrays, where each spot is a single, defined chemical entity. We have previously described functionalized microarray slides capable of rapid and high-throughput screening of over 5000 different chemical compounds binding to living bacteria, including quantitation of binding parameters [19-21]. In this study, we optimized the key experimental parameters for screening living mammalian cells using known small molecule ligands on the previously developed SMM, which requires simultaneous optimization of ligand presentation, the effect of motion, incubation time, ligand concentration, and the number of panned cells.

\section{Experimental Section}

\subsection{Chemicals and Microarray}

All chemicals were American Chemical Society grade or higher and commercially available unless noted otherwise. We previously provided details on the microarray slide, which uses $N$-hydroxysuccinimide modified polyethylene glycol (PEG-NHS) for both conjugation of potential ligands and presentation of ligands far from the glass surface [20]. All ligands were engineered to contain a single nucleophilic group (i.e., primary amine) and were dissolved as stock solutions in 70\%/30\% (V/V) glycerol:dimethyl sulfoxide (DMSO, Sigma, St Louis, MO, USA) at a concentration of 0.1-1.0 mM. The $\mathrm{pH}$ was adjusted to be $\approx 9.0$ using diisopropylethylamine (DIEA, Sigma) to promote nucleophilic substitution using the primary amine. Polyallrylamine (PAAm, Sigma) was used as a positive control for cell binding at $10 \mathrm{mg} / \mathrm{mL}$ in $100 \mathrm{mM}$ sodium bicarbonate buffer ( $\mathrm{pH} \mathrm{9.0).}$ Cyclo Arg-Gly-Asp-D-Tyr-Lys (cRGDyk) peptide was purchased from AnaSpec, Inc. (Fremont, CA, USA). 2[(3-amino-3-carboxypropyl)(hydroxy)(phosphinyl)-methyl]pentane-1,5-dioic acid (GPI), 2-(3-(5-amino-1-carboxypentyl)ureido)pentanedioic acid (KUE), beta Ala-Gly ( $\beta$-AG) and all trimeric ligands were in house compounds, which were synthesized as previously described [22,23]. The ligand solution was distributed into a 384-well plate and printed on the NHS functionalized slide surface [20] using a microarray robot (OmniGrid Accent, DigiLab, Inc., Holliston, MA, USA) mounted with SMP11 pins (Telechem, Sunnyvale, CA, USA). The spreading of spots was optimized to be $300 \pm 10 \mu \mathrm{m}$ in diameter, with a center-to-center spacing of $500 \mu \mathrm{m}$ (i.e., 200- $\mu \mathrm{m}$ of clear space between any two spots). After incubating for $3 \mathrm{~h}$ at room temperature in air, the slides were immersed in deionized water 
to deactivate unreacted NHS groups. After washing with ethanol, the slides were dried under a nitrogen stream and stored in a dust free environment before use.

\subsection{Cell Culture and Adhesion Assay}

Melanoma cell lines including M21, M21-L, and B16 were grown in DMEM supplemented with $10 \%$ fetal bovine serum (FBS) and 100 units/mL penicillin/streptomycin $(\mathrm{P} / \mathrm{S})$ under $5 \% \mathrm{CO}_{2}$ at $37{ }^{\circ} \mathrm{C}$. Human prostate cancer cells, LNCaP and PC3, were cultured in RPMI supplemented with 10\% FBS and 100 units $/ \mathrm{mL} \mathrm{P/S}$ under $10 \% \mathrm{CO}_{2}$ at $37^{\circ} \mathrm{C}$. All cells were plated into $100-\mathrm{mm}$ culture dishes (Corning, Tewksbury, MA, USA) in $10 \mathrm{~mL}$ of pre-warmed culture media. When the cells reached $70 \%-80 \%$ confluence at a density of $2-5 \times 10^{6}$ cells/dish, either ESNF10 (700 nm NIR fluorophore) [24] or IR786 (800 nm NIR fluorophore) [21] was added to the dish at $2 \mu \mathrm{M}$ in media. After $20 \mathrm{~min}$ incubation at $37{ }^{\circ} \mathrm{C}$, the cells were washed twice with media and the NIR fluorescence signals were observed under a multi-channel fluorescence microscope (see below). The cells were then trypsinized and seeded onto the ligand-bearing surface in DMEM containing $10 \%$ FBS at $37{ }^{\circ} \mathrm{C}$. Incubation parameters, including the effect of rocking ( 0 vs. $30 \mathrm{rpm})$, incubation time (30-180 min), presented ligand concentration at the time of spotting $(0.1-1.0 \mathrm{mM})$, and applied cell density $\left(0.2 \times 10^{6}-8 \times 10^{6}\right.$ cells), were systematically optimized. After incubation, the slides were gently washed with cell culture media before scoring.

\subsection{Fluorescence Microscopy and Software}

Living cells bound to chemical spots were imaged using a Nikon TE2000 epifluorescence microscope equipped with a $75 \mathrm{~W}$ Xenon light source and an Orca-ER (Hamamatsu, Bridgewater, NJ, USA) camera [25,26]. Two custom filter sets (Chroma Technology Corporation, Brattleboro, VT, USA) composed of $650 \pm 22 \mathrm{~nm}$ and $750 \pm 25 \mathrm{~nm}$ excitation filters, $675 \mathrm{~nm}$ and $785 \mathrm{~nm}$ dichroic mirrors, and $710 \pm 25 \mathrm{~nm}$ and $810 \pm 20 \mathrm{~nm}$ emission filters were, respectively, used to detect ESNF10 (700 nm, pseudo-colored in red) and IR786 (800 nm, pseudo-colored in lime green) emission. For high-throughput imaging of microarrays, we have previously developed an automated microscope stage and software [21]. The complete scanning time for one microarray slide containing 5076 spots was approximately $2 \mathrm{~h}$ ( $1 \mathrm{~s}$ per spot plus stage movement time) using the automated microscope. IPLab 3.6 software (Nikon Inc., Melville, NY, USA) and ImageJ 1.45q (NIH, Bethesda, MD, USA) were used for normalization and autosegmentation of the fluorescence intensity of each spot. Sequential procedures for scoring were defined through region-of-interest (ROI) selection, static thresholding, binary image, and auto-counting. Data plotting was performed using Prism version 4.0a software (GraphPad, San Diego, CA, USA) and Microsoft Excel (Redmond, WA, USA).

\section{Results and Discussion}

\subsection{Live Cell Imaging and Controls}

To validate the assay, integrin $\alpha_{\mathrm{v}} \beta_{3}$-positive M21 cells (positive control) labeled with the $700 \mathrm{~nm}$ NIR fluorophore ESNF10 and integrin $\alpha_{v} \beta_{3}$-negative M21-L cells (negative control) labeled with the $800 \mathrm{~nm}$ NIR fluorophore IR786 were panned over the surface of our SMM (Figure 1A). PAAm, a 
"sticky" cationic polymer showing no specificity to cell surfaces was used as a positive ligand control, which bound all cell types. Using dual-channel NIR fluorescence microscopy, the number of individual cells binding each spot could be counted (Figure 1B). Thus the readout of our assay was number of cells bound per spot, with the theoretical maximum number of bound cells (i.e., the dynamic range of the assay) being defined by the PAAm control spots $(\approx 300$ cells per spot for all cell lines tested).

Results of the assay using the integrin-binding peptide cRGDyK as the ligand spot are shown in Figure 1B. Specificity was defined in one of two ways. In the absence of negative control cells, specificity was the number of receptor-positive cells binding a ligand spot divided by the number of these same cells binding inter-spot blank space on the slide. In the presence of negative control cells, specificity was the number of receptor-positive cells binding a ligand spot minus the number of receptor-negative cells bound to that same spot. Sensitivity was defined as the absolute number of receptor-positive cells bound to a particular spot. Of note, pseudo-coloring of $700 \mathrm{~nm}$ fluorescence in red and the $800 \mathrm{~nm}$ fluorescence in green permitted rapid visual assessment of specificity as demonstrated in Figure 1.

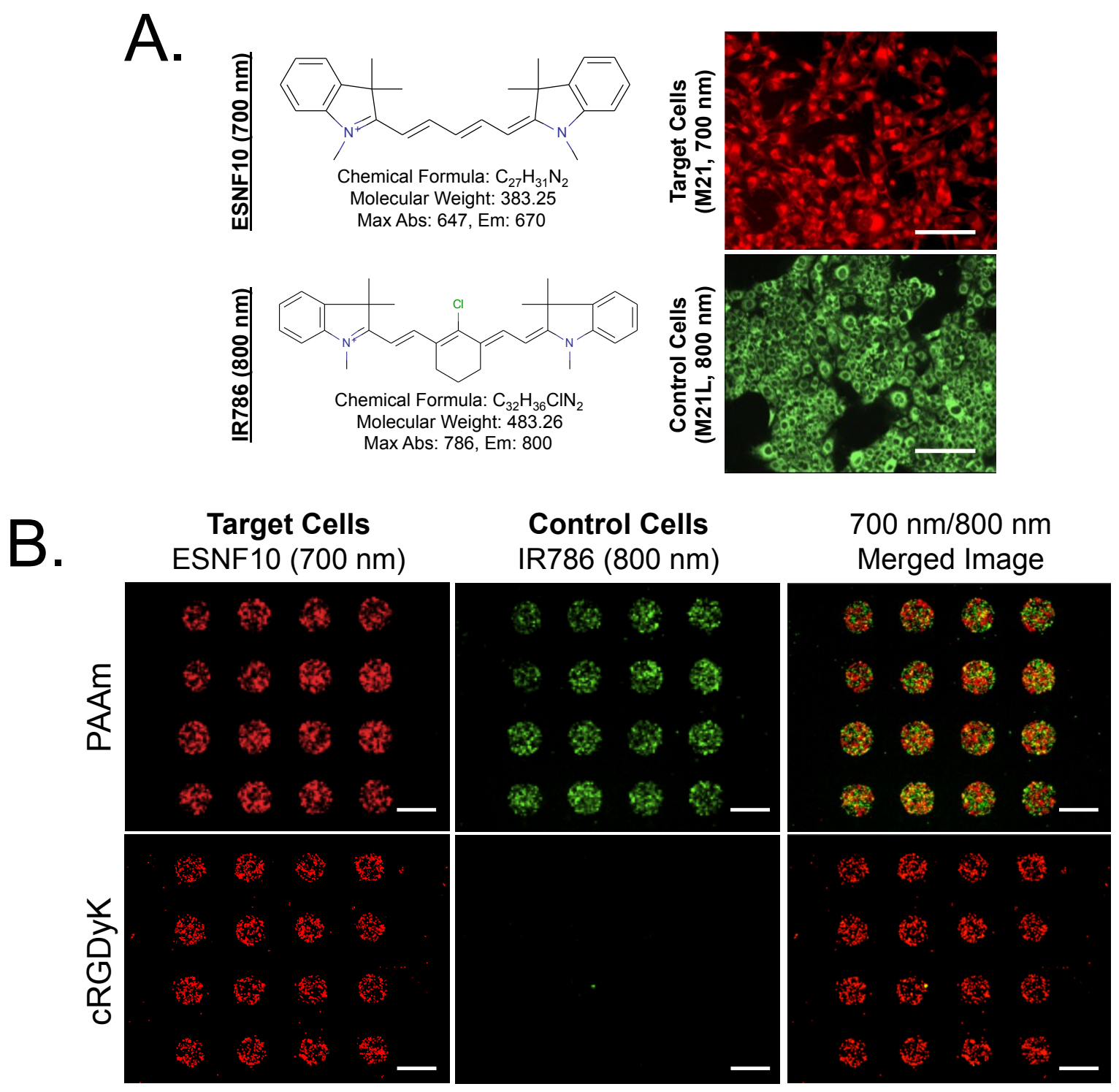


Figure 1. Dual-channel screening strategy and controls. (A) Living integrin $\alpha_{\mathrm{v}} \beta_{3}$-positive M21 cells (target cells; stained with ESNF10 and pseudo-colored in red) and integrin $\alpha_{\mathrm{v}} \beta_{3}$-negative M21-L cells (control cells; stained with IR786 and pseudo-colored in green) prior to dissociation from their respective plates. Scale bars $=100 \mu \mathrm{m}$. (B) The same cells mixed together and panned over PAAm positive control spots (top row) or cRGDyK ligand spots (bottom row). The yellow color indicates co-localized M21 and M21-L cells. Scale bars $=300 \mu \mathrm{m}$.

\subsection{Optimization of SMM Screening Using Living Cells}

In order to optimize screening parameters of our SMM using living cells, cRGDyK spots were arrayed, and a mixture of M21 and M21-L cells were applied while systematically varying motion, incubation time, ligand spotting concentration, and number of panned cells (Figure 2A). Notably, cell binding was greatly improved in the absence of motion, a result that might be explained by a boundary layer of shear stress created immediately above the surface of the slide in the presence of motion. Once stationary, cell binding increased linearly with incubation time up to $120 \mathrm{~min}$, at which time saturation occurred. Cell binding also increased as a function ligand spotting concentration, with saturation occurring above $0.25 \mathrm{mM}$. The number of panned cells also increased binding, with saturation occurring at $4 \times 10^{6}$ cells per slide. To maximize the specificity of binding, we compared incubation in the presence or absence of $10 \%$ serum, and with or without negative control cells (Figure 2B). Both serum and competing cells improved specificity, likely by blocking non-specific interactions.

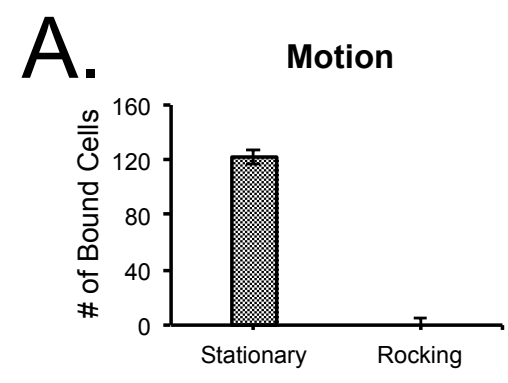

Ligand Concentration

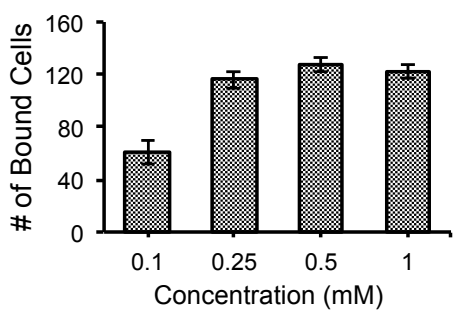

Incubation Time

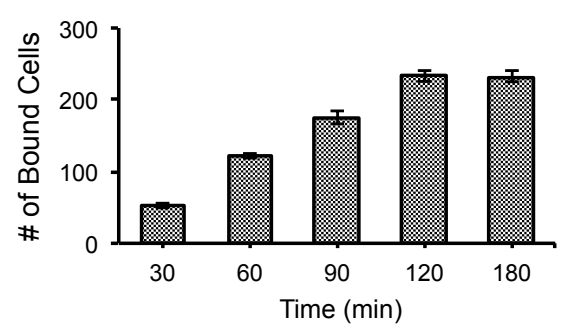

Number of Panning Cells

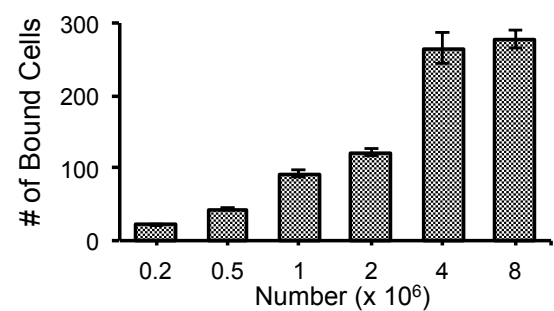

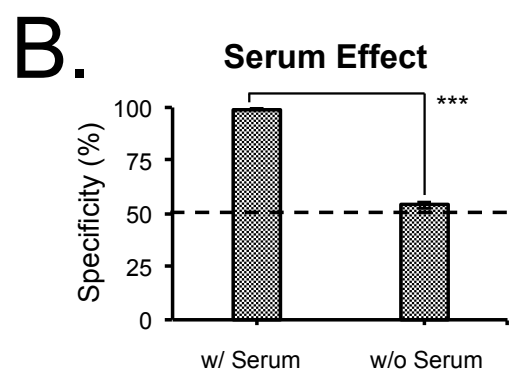

Competition Effect

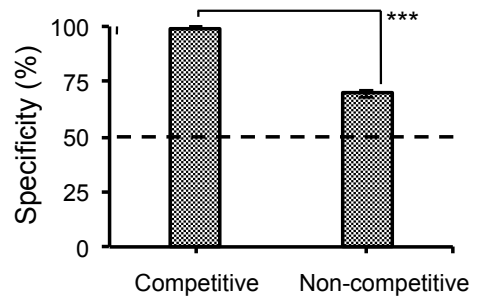

Figure 2. Optimization of screening parameters: (A) Maximizing sensitivity through the effect of motion, incubation time, ligand spotting concentration, and the number of panned cells using a cRGDyK array and a mixture of M21 and M21-L cells. Shown are mean \pm SD for each data point from 4 randomly chosen spots on the slide. (B) Maximizing specificity through the use of serum or competing receptor-negative cells. 


\subsection{Screening of Diverse Chemical and Cellular Interactions}

To explore the usefulness of our SMM screening system, we tested three cell-ligand interactions, which all differed in terms of cell type, receptor type, ligand type, and $\mathrm{B}_{\max }$ (i.e., the number of receptors per cell) and are shown in Figure 3 and summarized in Table 1. M21 cells have approximately $5 \times 10^{4}$ integrin $\alpha_{v} \beta_{3}$ receptors per cell (i.e., $\mathrm{B}_{\max }$ ) on their surface, while M21-L cells have no detectable integrin $\alpha_{v} \beta_{3}$ receptors $\left(1 \times 10^{3}\right)$ [27]. Integrin $\alpha_{v} \beta_{3}$ has a type I transmembrane topology and binds the cyclic peptide ligand cRGDyK with an affinity of approximately $50 \mathrm{nM}$. LNCaP cells have approximately $2 \times 10^{5}$ prostate-specific membrane antigen (PSMA) receptors per cell on their surface, while PC3 cells have no detectable PSMA [28]. PSMA has a type II transmembrane topology and binds the small molecule KUE with an affinity of approximately $15 \mathrm{nM}$. B16 cells have approximately $7 \times 10^{3}$ melanocortin 1 receptors $(\mathrm{MC} 1 \mathrm{R})$ receptors per cell on their surface, while LNCaP cells have no detectable MC1R [29]. MC1R is a G protein-coupled receptor with 7 transmembrane domains and binds the peptide $\alpha$-melanocyte stimulating hormone ( $\alpha$-MSH) with an affinity of approximately $0.4 \mathrm{nM}$. Using the optimized parameters from Figure 2 (no motion, 60 min incubation time, $1 \mathrm{mM}$ ligand spotting concentration, and $4 \times 10^{6}$ panned cells per slide), all three cell-ligand interactions are detectable with our SMM screening system with relatively high specificity and with sensitivity proportional to $\mathrm{B}_{\max }$.

It should be noted, however, that many of the system parameters are inter-dependent and should be re-optimized for a particular model system. For example, in the presence of extremely high affinity and $\mathrm{B}_{\max }$, motion might not only be possible but could improve specificity by reducing non-specific interactions. Similarly, we only explored the presence or absence of $10 \%$ serum, but in some model systems, a higher or lower concentration could be optimal.

Table 1. Selected small molecule ligands and cell lines used for SMM screening.

\begin{tabular}{|c|c|c|c|c|c|}
\hline Compound & $\begin{array}{c}\text { M.W. } \\
(\mathbf{D a})\end{array}$ & $\begin{array}{c}\text { Affinity } \\
\left(\boldsymbol{K}_{\mathbf{D}}\right)\end{array}$ & $\begin{array}{c}\text { Specificity } \\
\text { (Receptor) }\end{array}$ & $\begin{array}{c}\text { Tested Cells } \\
\text { (Positive/Negative) }\end{array}$ & Ref. \\
\hline$\beta$-AG & 248.19 & $2 \mu \mathrm{M}$ & PSMA & LNCaP/PC3 & {$[22,23]$} \\
\hline$\beta$-AG trimer & 1213.20 & $60 \mathrm{nM}$ & PSMA & LNCaP/PC3 & {$[22,23]$} \\
\hline GPI & 311.23 & $9 \mathrm{nM}$ & PSMA & LNCaP/PC3 & {$[22,23]$} \\
\hline GPI trimer & 1360.23 & $0.7 \mathrm{nM}$ & PSMA & LNCaP/PC3 & {$[22,23]$} \\
\hline KUE & 319.31 & $15 \mathrm{nM}$ & PSMA & LNCaP/PC3 & {$[28]$} \\
\hline cRGDyK & 619.67 & $50 \mathrm{nM}$ & Integrin $\alpha_{v} \beta_{3}$ & M21/M21-L & {$[30]$} \\
\hline$\alpha-M S H$ & 1664.88 & $0.4 \mathrm{nM}$ & MC1R & B16/LNCaP & {$[29]$} \\
\hline PAAm & $\sim 70,000$ & N.A. & Nonspecific & All Cells & {$[21]$} \\
\hline
\end{tabular}

$\beta$-AG, beta Ala-Gly; cRGDyk, cyclo Arg-Gly-Asp-D-Tyr-Lys; GPI, 2[(3-amino-3-carboxypropyl)(hydroxy)(phosphinyl)methyl]pentane-1,5-dioic acid; KUE, 2-(3-(5-amino-1-carboxypentyl)ureido)pentanedioic acid; MC1R, melanocortin 1 receptors; $\alpha$-MSH, $\alpha$-melanocyte stimulating hormone; M.W., molecular weight; N.A., not applicable; PAAm, polyallrylamine; PSMA, prostate-specific membrane antigen.

\subsection{Exploring the Relationship between Ligand Affinity and $B_{\max }$}

The results from Figure 3 suggested that ligand affinity $\left(K_{\mathrm{D}}\right)$, and therefore the ratio of affinity to $\mathrm{B}_{\max }$, might have a profound impact on the sensitivity of the SMM screening assay. To explore this relationship we utilized a series of PSMA ligands previously reported by our group (Figure 4A), which spanned a wide range of affinity [22,31]: $\beta$-AG $\left(K_{\mathrm{D}}=2 \mu \mathrm{M}\right)$, GPI $\left(K_{\mathrm{D}}=9 \mathrm{nM}\right), \beta-\mathrm{AG}$ trimer 
$\left(K_{\mathrm{D}}=60 \mathrm{nM}\right)$, and GPI trimer $\left(K_{\mathrm{D}}=0.4 \mathrm{nM}\right)$. The SMM was probed with PSMA-positive cells (LNCaP) and PSMA-negative cells (PC3), using the optimized parameters described for Figure 3. As shown in Figure 4, the SMM assay was able to perform well over 3 logs of affinity space, with the number of cells bound per spot being proportional to affinity. These results reinforce the importance of defining any cell-bound ligand spot as "positive" during initial screening of diverse chemical libraries because low affinity ligands might have only a few cells bound. And, if $\mathrm{B}_{\max }$ is low, even high affinity interactions may result in only a few cells bound per spot [22,31].
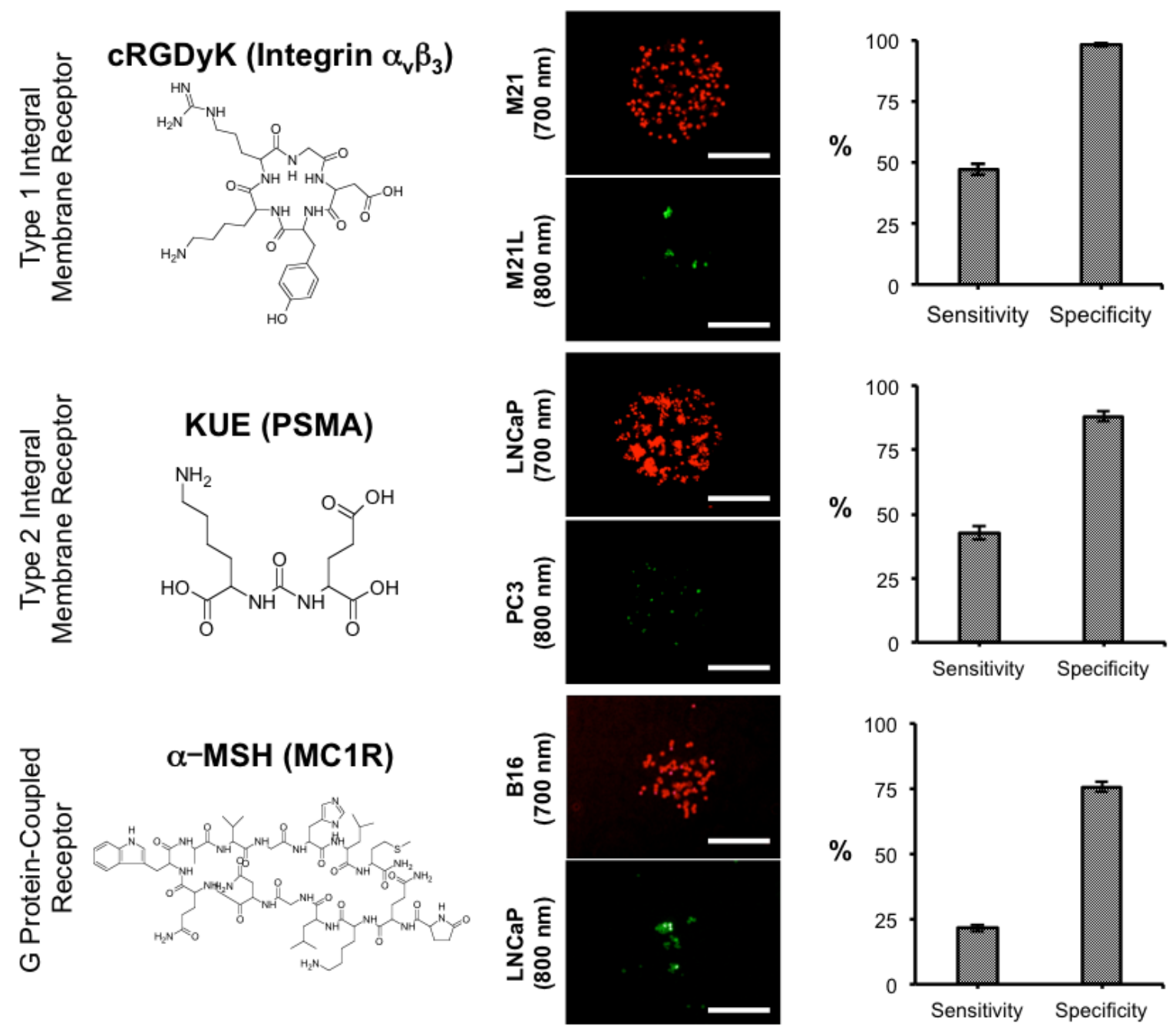

Figure 3. Robustness of the SMM Screening Assay: Three different model systems, varying in ligand chemical structure, cell type, receptor transmembrane topology, $\mathrm{B}_{\max }$, and ligand affinity were tested as described in the text. Shown are mean \pm SD for each data point from four randomly chosen spots on the slide. Receptor-positive and receptor-negative cells were labeled with $700 \mathrm{~nm}$ and $800 \mathrm{~nm}$ NIR fluorophores and pseudo-colored red and green, respectively, during microscopy. Scale bars $=200 \mu \mathrm{m}$. 

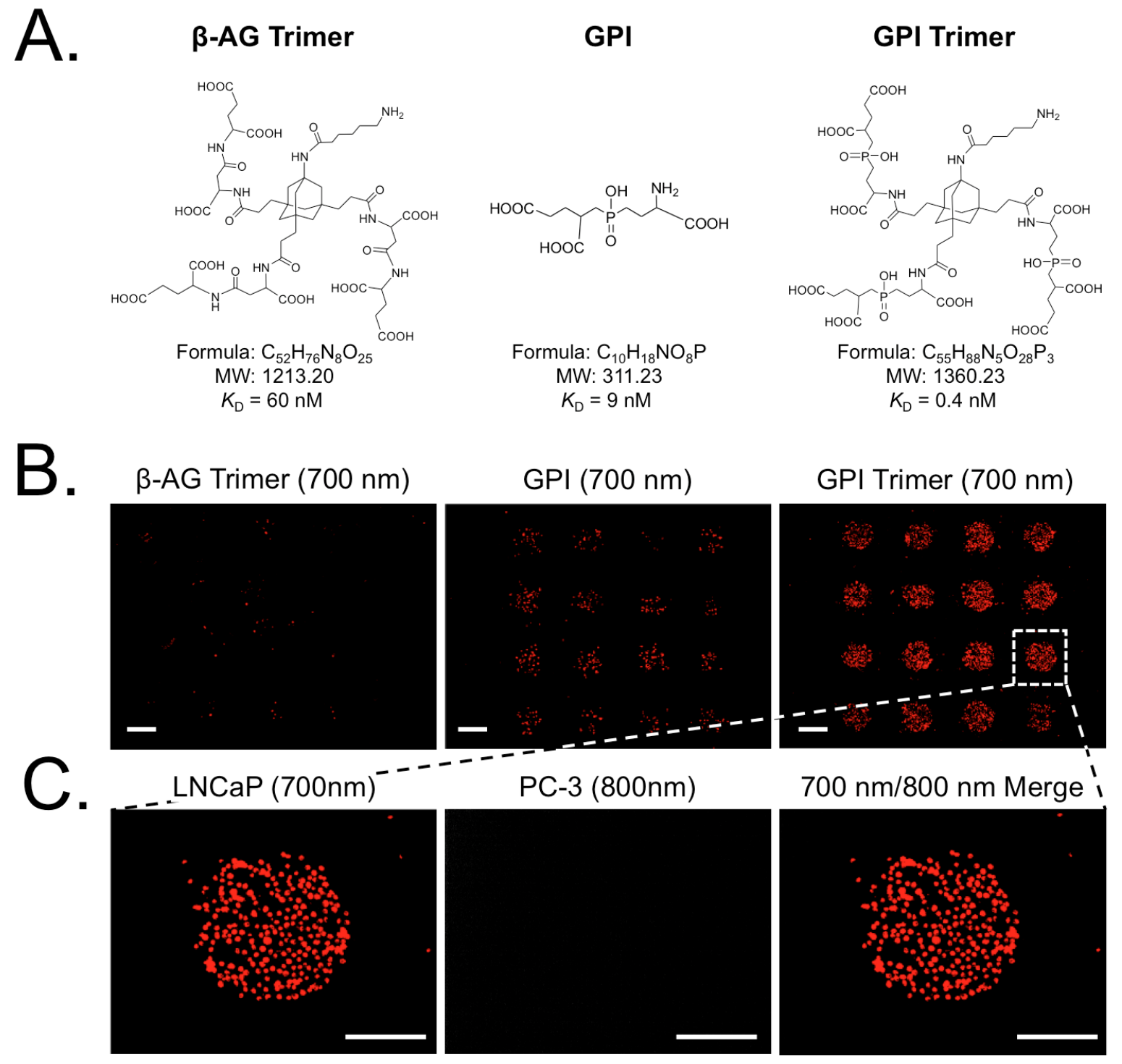

Figure 4. The effect of affinity on cell-ligand spot binding: PSMA-positive LNCaP cells and PSMA-negative PC3 cells were labeled with $700 \mathrm{~nm}$ and $800 \mathrm{~nm}$ NIR fluorophores and pseudo-colored in red and green, respectively. (A) Chemical structures of targeting ligands employed, (B) $4 \times$ microscopy images, and (C) $20 \times$ microscopy images. Scale bars $=200 \mu \mathrm{m}$.

\section{Conclusions}

We have developed a SMM glass slide-based system for the rapid and efficient screening of ligands that bind to the surface of living mammalian cells. If careful attention is paid to critical parameters, the system appears to function well over a wide range of ligand affinities, receptor topologies, and cell types of interest. It is hoped that this system can be applied to the screening of diverse and complex chemical libraries to find lead candidates for improved diagnostic and therapeutic drugs. 


\section{Acknowledgments}

We thank Marsha Paul and Paul White (DigiLab, Ann Arbor, MI, USA), Hak Guen Lee (Facom, South Korea), Alex Allardyce (ChemAxon, Budapest, Hungary), and Colin Johnson (LAE Technologies, Barrie, Canada) for technical support and many helpful discussions, David J. Burrington, Jr. for editing, and Eugenia Trabucchi for administrative assistance. This study was supported by a grant from the Nehemias Gorin Foundation and the following grants from the National Institutes of Health: NCI BRP grant \#R01-CA-115296 (JVF) and NIBIB grant \#R01-EB-011523 (HSC). The content expressed is solely the responsibility of the authors and do not necessarily represent the official views of the National Institutes of Health.

\section{Author Contributions}

JHL, KB and HSC performed the experiments. JHL, JVF and HSC reviewed, analyzed, and interpreted the data. JHL, JVF and HSC wrote the paper. All authors discussed the results and commented on the manuscript.

\section{Conflicts of Interest}

Frangioni is currently CEO of Curadel, LLC, a for-profit company that has licensed FLARE technology from Beth Israel Deaconess Medical Center.

\section{References}

1. Christopoulos, A. Allosteric binding sites on cell-surface receptors: Novel targets for drug discovery. Nat. Rev. Drug Discov. 2002, 1, 198-210.

2. Overington, J.P.; Al-Lazikani, B.; Hopkins, A.L. How many drug targets are there? Nat. Rev. Drug Discov. 2006, 5, 993-996.

3. Geysen, H.M.; Schoenen, F.; Wagner, D.; Wagner, R. Combinatorial compound libraries for drug discovery: An ongoing challenge. Nat. Rev. Drug Discov. 2003, 2, 222-230.

4. Patel, D.V.; Godon, E.M. Applications of small-molecule combinatorial chemistry to drug discovery. Drug Discov. Today 1996, 1, 134-144.

5. Schreiber, S.L. Target-oriented and diversity-oriented organic synthesis in drug discovery. Science 2000, 287, 1964-1969.

6. Lam, K.S.; Salmon, S.E.; Hersh, E.M.; Hruby, V.J.; Kazmierski, W.M.; Knapp, R.J. A new type of synthetic peptide library for identifying ligand-binding activity. Nature 1991, 354, 82-84.

7. Uttamchandani, M.; Walsh, D.P.; Yao, S.Q.; Chang, Y.T. Small molecule microarrays: Recent advances and applications. Curr. Opin. Chem. Biol. 2005, 9, 4-13.

8. Ma, H.; Horiuchi, K.Y. Chemical microarray: A new tool for drug screening and discovery. Drug Discov. Today 2006, 11, 661-668.

9. Barnes-Seeman, D.; Park, S.B.; Koehler, A.N.; Schreiber, S.L. Expanding the functional group compatibility of small-molecule microarrays: Discovery of novel calmodulin ligands. Angew Chem. Int. Ed. Engl. 2003, 42, 2376-2379. 
10. Uttamchandani, M.; Walsh, D.P.; Khersonsky, S.M.; Huang, X.; Yao, S.Q.; Chang, Y.T. Microarrays of tagged combinatorial triazine libraries in the discovery of small-molecule ligands of human IgG. J. Combin. Chem. 2004, 6, 862-868.

11. Wu, H.; Ge, J.; Uttamchandani, M.; Yao, S.Q. Small molecule microarrays: The first decade and beyond. Chem. Comm. 2011, 47, 5664-5670.

12. Bradner, J.E.; McPherson, O.M.; Mazitschek, R.; Barnes-Seeman, D.; Shen, J.P.; Dhaliwal, J.; Stevenson, K.E.; Duffner, J.L.; Park, S.B.; Neuberg, D.S.; et al. A robust small-molecule microarray platform for screening cell lysates. Chem. Biol. 2006, 13, 493-504.

13. Pop, M.S.; Wassaf, D.; Koehler, A.N. Probing small-molecule microarrays with tagged proteins in cell lysates. Curr. Protoc. Chem. Biol. 2014, 6, 209-220.

14. Shi, H.; Uttamchandani, M.; Yao, S.Q. Applying small molecule microarrays and resulting affinity probe cocktails for proteome profiling of mammalian cell lysates. Chem. Asian J. 2011, 6, 2803-2815.

15. El-Ali, J.; Sorger, P.K.; Jensen, K.F. Cells on chips. Nature 2006, 442, 403-411.

16. Rantala, J.B.; Kwon, S.; Korkola, J.; Gray, J.W. Expanding the diversity of imaging-based rnai screen applications using cell spot microarrays. Microarrays 2013, 2, 97-114.

17. Kim, J.; Taylor, D.; Agrawal, N.; Wang, H.; Kim, H.; Han, A.; Rege, K.; Jayaraman, A. A programmable microfluidic cell array for combinatorial drug screening. Lab Chip 2012, 12, $1813-1822$.

18. Chen, D.S.; Davis, M.M. Molecular and functional analysis using live cell microarrays. Curr. Opin. Chem. Biol. 2006, 10, 28-34.

19. Lee, J.H.; Choi, H.S.; Nasr, K.A.; Ha, M.; Kim, Y.; Frangioni, J.V. High-throughput small molecule identification using maldi-tof and a nanolayered substrate. Anal. Chem. 2011, 83, 5283-5289.

20. Lee, J.H.; Hyun, H.; Cross, C.J.; Henary, M.; Nasr, K.A.; Oketokoun, R.; Choi, H.S.; Frangioni, J.V. Rapid and facile microwave-assisted surface chemistry for functionalized microarray slides. Adv. Funct. Mater. 2012, 22, 872-878.

21. Lee, J.H.; Park, S.; Hyun, H.; Bordo, M.W.; Oketokoun, R.; Nasr, K.A.; Frangioni, J.V.; Choi, H.S. High-throughput screening of small molecule ligands targeted to live bacteria surface. Anal. Chem. 2013, 85, 3508-3514.

22. Humblet, V.; Misra, P.; Bhushan, K.R.; Nasr, K.; Ko, Y.S.; Tsukamoto, T.; Pannier, N.; Frangioni, J.V.; Maison, W. Multivalent scaffolds for affinity maturation of small molecule cell surface binders and their application to prostate tumor targeting. J. Med. Chem. 2009, 52, 544-550.

23. Kozikowski, A.P.; Zhang, J.; Nan, F.; Petukhov, P.A.; Grajkowska, E.; Wroblewski, J.T.; Yamamoto, T.; Bzdega, T.; Wroblewska, B.; Neale, J.H. Synthesis of urea-based inhibitors as active site probes of glutamate carboxypeptidase ii: Efficacy as analgesic agents. J. Med. Chem. 2004, 47, 1729-1738.

24. Kim, S.H.; Park, G.; Hyun, H.; Lee, J.H.; Ashitate, Y.; Choi, J.; Hong, G.H.; Owens, E.A.; Henary, M.; Choi, H.S. Near-infrared lipophilic fluorophores for tracing tissue growth. Biomed. Mater. 2013, 8, 014110. 
25. Choi, H.S.; Ashitate, Y.; Lee, J.H.; Kim, S.H.; Matsui, A.; Insin, N.; Bawendi, M.G.; SemmlerBehnke, M.; Frangioni, J.V.; Tsuda, A. Rapid translocation of nanoparticles from the lung airspaces to the body. Nat. Biotechnol. 2010, 28, 1300-1303.

26. Choi, H.S.; Gibbs, S.L.; Lee, J.H.; Kim, S.H.; Ashitate, Y.; Liu, F.; Hyun, H.; Park, G.; Xie, Y.; Bae, S.; et al. Targeted zwitterionic near-infrared fluorophores for improved optical imaging. Nat. Biotechnol. 2013, 31, 148-153.

27. Cressman, S.; Dobson, I.; Lee, J.B.; Tam, Y.Y.; Cullis, P.R. Synthesis of a labeled rgd-lipid, its incorporation into liposomal nanoparticles, and their trafficking in cultured endothelial cells. Bioconjugate Chem. 2009, 20, 1404-1411.

28. Hillier, S.M.; Maresca, K.P.; Femia, F.J.; Marquis, J.C.; Foss, C.A.; Nguyen, N.; Zimmerman, C.N.; Barrett, J.A.; Eckelman, W.C.; Pomper, M.G.; et al. Preclinical evaluation of novel glutamateurea-lysine analogues that target prostate-specific membrane antigen as molecular imaging pharmaceuticals for prostate cancer. Cancer Res. 2009, 69, 6932-6940.

29. Chen, J.; Cheng, Z.; Hoffman, T.J.; Jurisson, S.S.; Quinn, T.P. Melanoma-targeting properties of $(99 \mathrm{~m})$ technetium-labeled cyclic alpha-melanocyte-stimulating hormone peptide analogues. Cancer Res. 2000, 60, 5649-5658.

30. Chen, X.; Park, R.; Tohme, M.; Shahinian, A.H.; Bading, J.R.; Conti, P.S. Micropet and autoradiographic imaging of breast cancer alpha v-integrin expression using $18 \mathrm{f}$ - and $64 \mathrm{cu}-$ labeled rgd peptide. Bioconjugate Chem. 2004, 15, 41-49.

31. Misra, P.; Humblet, V.; Pannier, N.; Maison, W.; Frangioni, J.V. Production of multimeric prostate-specific membrane antigen small-molecule radiotracers using a solid-phase 99mtc preloading strategy. J. Nucl. Med. 2007, 48, 1379-1389.

(C) 2015 by the authors; licensee MDPI, Basel, Switzerland. This article is an open access article distributed under the terms and conditions of the Creative Commons Attribution license (http://creativecommons.org/licenses/by/4.0/). 